\title{
Article \\ Catalytic Descriptors to Investigate Catalytic Power in the Reaction of Haloalkane Dehalogenase Enzyme with 1,2-Dichloroethane
}

\author{
Xin Xin, Chen Li, Delu Gao and Dunyou Wang *D \\ College of Physics and Electronics, Shandong Normal University, Jinan 250014, China; \\ xin@stu.sdnu.edu.cn (X.X.); lichen8@stu.sdnu.edu.cn (C.L.); gaodelu@stu.sdnu.edu.cn (D.G.) \\ * Correspondence: dywang@sdnu.edu.cn
}

check for updates

Citation: Xin, X.; Li, C.; Gao, D.; Wang, D. Catalytic Descriptors to Investigate Catalytic Power in the Reaction of Haloalkane Dehalogenase Enzyme with 1,2-Dichloroethane. Int J. Mol. Sci. 2021, 22, 5854. https:// doi.org/10.3390/ijms22115854

Academic Editor: Andrea Salis

Received: 27 April 2021

Accepted: 27 May 2021

Published: 29 May 2021

Publisher's Note: MDPI stays neutral with regard to jurisdictional claims in published maps and institutional affiliations.

Copyright: (c) 2021 by the authors. Licensee MDPI, Basel, Switzerland. This article is an open access article distributed under the terms and conditions of the Creative Commons Attribution (CC BY) license (https:/ / creativecommons.org/licenses/by/ $4.0 /)$.
Abstract: Enzymes play a fundamental role in many biological processes. We present a theoretical approach to investigate the catalytic power of the haloalkane dehalogenase reaction with 1,2dichloroethane. By removing the three main active-site residues one by one from haloalkane dehalogenase, we found two reactive descriptors: one descriptor is the distance difference between the breaking bond and the forming bond, and the other is the charge difference between the transition state and the reactant complex. Both descriptors scale linearly with the reactive barriers, with the three-residue case having the smallest barrier and the zero-residue case having the largest. The results demonstrate that, as the number of residues increases, the catalytic power increases. The predicted free energy barriers using the two descriptors of this reaction in water are 23.1 and $24.2 \mathrm{kcal} / \mathrm{mol}$, both larger than the ones with any residues, indicating that the water solvent hinders the reactivity. Both predicted barrier heights agree well with the calculated one at $25.2 \mathrm{kcal} / \mathrm{mol}$ using a quantum mechanics and molecular dynamics approach, and also agree well with the experimental result at $26.0 \mathrm{kcal} / \mathrm{mol}$. This study shows that reactive descriptors can also be used to describe and predict the catalytic performance for enzyme catalysis.

Keywords: enzyme catalysis; reactive descriptor; catalytic power; nucleophilic substitution reaction; reaction path; transition state; $\mathrm{S}_{\mathrm{N}} 2$ reaction

\section{Introduction}

Enzyme catalysis not only plays an essential role in life processes [1,2], but also is of crucial importance in environmental detoxification processes [3]. Thus, to understand the catalytic power of enzymes on an atomic level is fundamentally important. In general, there have been many proposals to elucidate the catalytic power of enzymes [4-6]. The two most common explanations are electrostatic effects [4,7-10] and dynamical effects [11-17]. The electrostatic effects' explanations emphasize that the most important catalytic factor is the stabilization of the transition state by electrostatic preorganization of the enzyme active site and that other effects usually are relatively small. The dynamical effects' explanations state that the enzyme plays a role to optimize a particular vibrational mode for moving the system to the transition state, or for converting a system at the transition state to the product state. However, there has been no consensus on the catalytic effects of enzymes.

In environmental detoxification, the enzyme haloalkane dehalogenase (DhlA), isolated from bacterial enzyme Xanthobacter autotrophicus GJ10 [3], is involved in degrading a major pollutant 1,2-dichloroethane (DCE). In recent years, its substrate specificity [18], genetics $[19,20]$, structure $[21,22]$ and catalytic mechanism have been extensively studied. Nonetheless, the origin of the enzyme power is still ambiguous [6]. The first step of its reaction mechanism is a nucleophilic substitution reaction $\left(\mathrm{S}_{\mathrm{N}} 2\right)$ as the side chain aspartic acid residue Asp124 (Asp $-\mathrm{CO}_{2}^{-}$) in the DhlA attacks the DCE [23-28] to catalyze the displacement of $\mathrm{Cl}^{-}$. Franken et al. [21] determined the three-dimensional structure of 
DhlA and suggested that Asp124 is the nucleophile for the catalysis. Verschueren et al. [29] showed that catalysis by Dh1A is a two-step mechanism. The X-ray structure study by Schanstra et al. [23] proposed that, besides the residues of Trp125 and Trp175 in DhlA, Phe172 is also involved in stabilizing the activate site of the enzyme. Molecular modeling methods were carried out by Dambordky et al. $[24,25]$ to investigate the dehalogenase reaction mechanism and to determine the rate-limiting step. Theoretical simulations based on empirical valence bond potential were performed to study the catalytic effect of Dh1A [26] and found that the electrostatic effects are responsible for most of the catalytic effects. Several versions of quantum mechanics and molecular mechanics (QM/MM) $[27,28]$ as well as molecular dynamics (MD) [28] simulations were carried out to study the kinetic isotope effects [27], activation barriers [27,28,30], and comparison with the corresponding reaction in water $[4-6,13,27,28,30,31]$.

It is still computationally formidable to simulate the whole system at the pure quantum mechanics level. Thus, first, we replace the nucleophile Asp $-\mathrm{CO}_{2}^{-}$with $\mathrm{CH}_{3} \mathrm{CO}_{2}^{-}\left(\mathrm{AcO}^{-}\right)$ due to the fact they have the same active site; in addition, we simplify the three residues Trp125, Trp175 and Phe172 using their active sites to represent them as seen in Figure 1. Second, we take away the three residues one by one to investigate the reactive descriptors, to explain the catalytic power of enzyme DhlA in the $S_{N} 2$ step. Third, using the reactive descriptors, the reactive barrier of the corresponding $\mathrm{AcO}^{-}$attacking DCE reaction in a water environment is predicted, and compared with the one calculated using a quantum mechanics and molecular mechanics (QM/MM) method [32,33].

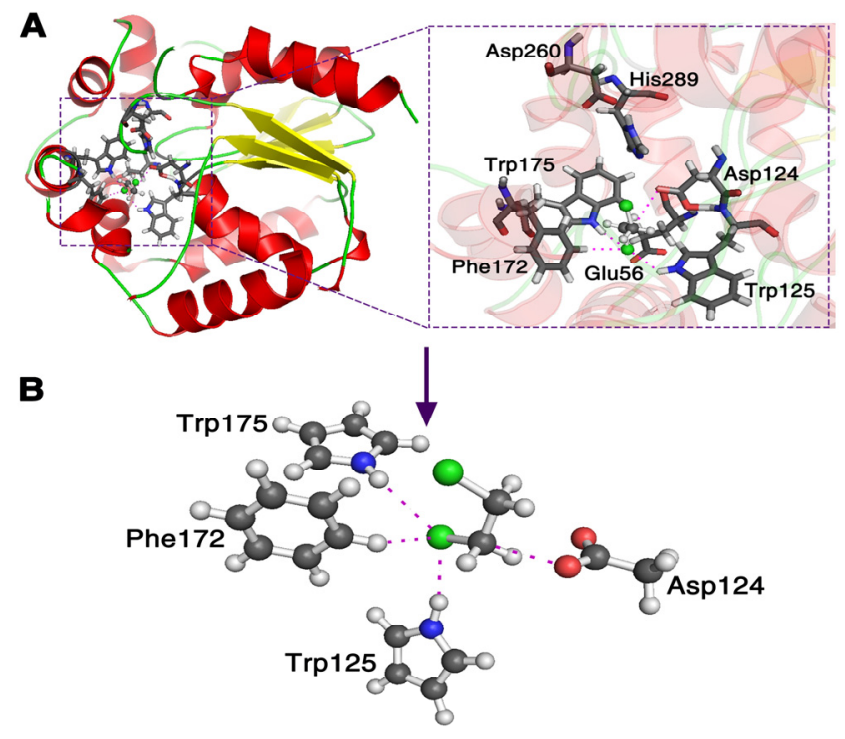

Figure 1. Theoretical model of the enzyme haloalkane dehalogenase (DhlA) catalytic reaction with 1,2-dichloroethane (PDB code 2DHC in (A)). The side chain Asp124 (Asp - $\mathrm{CO}_{2}^{-}$) in the DhlA is replaced with $\mathrm{CH}_{3} \mathrm{CO}_{2}^{-}$and three residues of Trp125, Trp175 and Phe172 are reduced using their active sites, respectively, in (B).

Reactive descriptors have been established, for the past two decades, to describe and predict the catalytic reaction on heterogeneous catalysis on surfaces [34]. Until now, the reactive descriptors studied have been mostly limited to metal, metal-oxide or other surfaces [35]. Here, the purpose of this paper is to extend the studies on the reactive descriptors to explain the catalytic power in enzyme catalysis. We present a theoretical study, for the first time using reactive descriptors, to investigate the catalytic power of Asp124 catalyzing DCE in the $\mathrm{S}_{\mathrm{N}} 2$ step. Moreover, we use the obtained descriptors to predict the performance of a water environment in this $\mathrm{S}_{\mathrm{N}} 2$ reaction, and use the obtained relationships between reactive descriptors and the activation barriers to predict the barrier of this $S_{N} 2$ reaction in water. 


\section{Results and Discussion}

\subsection{The Bond Breaking and Formation Descriptor}

Figure 2 shows the structures of the stationary points along the reaction pathways of the reactions with three (Trp125 + Phe172 + Trp175), two (Trp125 + Trp175), one (Trp125), and zero residues, respectively.
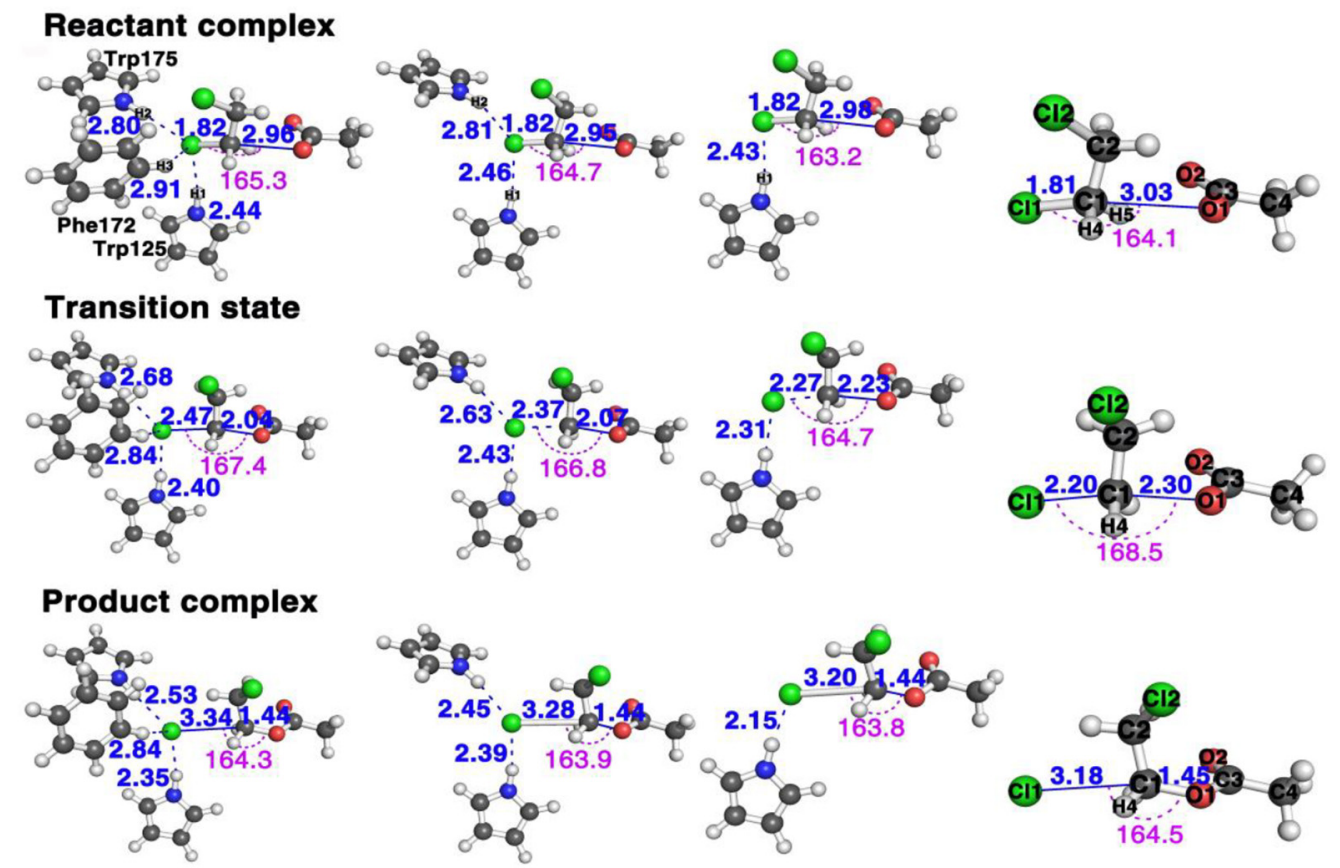

Figure 2. The structural comparison of the three stationary points, reactants (top row), transition states (middle row), and products (bottom row) of $\mathrm{AcO}^{-}+D C E$ reaction in the presence of, from left column to right column, three $(\operatorname{Trp} 125+$ Phe172 + Trp175), two $(\operatorname{Trp} 125+\operatorname{Trp} 175)$, one $(\operatorname{Trp} 125)$ and zero residues, respectively (see Figures S1-S5 for more detailed information of these geometries in the Supplementary Materials).

This $\mathrm{S}_{\mathrm{N}} 2$ mechanism has the concerted formation of the $\mathrm{O} 1-\mathrm{C} 1$ bond and the breaking of the $\mathrm{C} 1$ and $\mathrm{Cl1}$ leaving group. The faster the $\mathrm{C} 1-\mathrm{Cl} 1$ bond breaks and the $\mathrm{O} 1-\mathrm{C} 1$ forms, the faster it finishes the reaction, and the bigger the reactivity. In other words, we may say it has a "later" transition state. By comparing the transition state geometries, we can see which case has a faster bond breaking and bond formation process. First, let us define one parameter $D_{c a t}=d_{l}-d_{f}$ as the reactivity catalytic descriptor. Here, $d_{l}$ represents the distance between the leaving group $\mathrm{Cl} 1$ and $\mathrm{C} 1$ in the substrate and $d_{f}$ the forming distance between the $\mathrm{O} 1$ in the nucleophile and $\mathrm{C} 1$ in the substrate. Thus, $D_{\text {cat }}$ represents the difference between the breaking bond and the forming bond. The bigger the $D_{\text {cat }}$ value at the transition state, the faster the $\mathrm{Cl1}-\mathrm{C} 1$ bond breaks (the bigger the breaking bond distance) and the faster the $\mathrm{O} 1-\mathrm{C} 1$ bond forms (the shorter the forming bond distance); thus, the more "lateness" of the transition state and the larger the reactivity. More specifically, there should be a larger number of reactants passing the transition state per unit time according to the transition state theory [36], namely, the larger the turn-over frequency, which associates with a lower activation barrier. We can see that the $D_{\text {cat }}$ value is $0.43 \AA$ for the reaction with three residues, $0.30 \AA$ with two and only $0.04 \AA$ with one; thus, the reaction with the all three residues $(\operatorname{Trp} 125+$ Phe172 + Trp175) reacts the fastest, then the reaction with two (Trp125 + Trp175), with the reaction with only one (Trp125) having the smallest reactivity. This is proven by the free energy barriers, shown in Figure 3B with three, two, one and zero residues are 15.4, 17.1, 19.3, and $24.3 \mathrm{kcal} / \mathrm{mol}$, respectively, with the one with three residues having the smallest energy barrier and the one without any residues having the largest. 
A

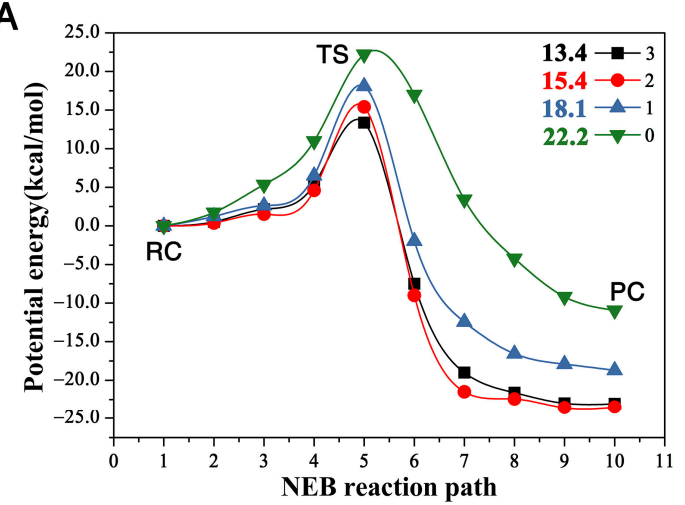

B

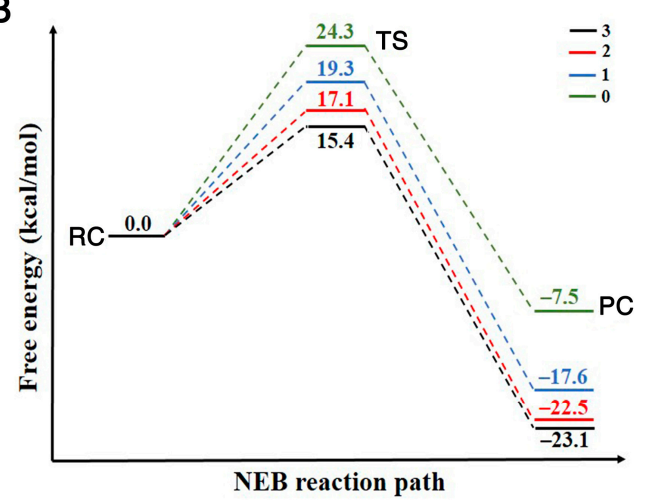

Figure 3. (A) is the potential energy of $A c O^{-}+D C E$ reaction in the presence of three (Trp125+ Phe172 + Trp175), two (Trp125 + Trp175), one (Trp125), and zero residues, along the NEB reaction path, respectively; (B) is a schematic plot of the reaction profile showing the free energies at the stationary points along the NEB reaction path. (RC, TS and PC repreScheme 0 . Å for the reaction without any residues. The order of this $D_{c a t}$ descriptor with different numbers of residues is $D_{\text {cat }}(3)>$ $D_{\text {cat }}(2)>D_{\text {cat }}(1)>D_{\text {cat }}(0)$. Therefore, this $D_{\text {cat }}$ behavior proves that the presence of the enzyme, even only with one residue, catalyzes the $\mathrm{S}_{\mathrm{N}} 2$ reaction of $A c \mathrm{O}^{-}+D C E$. The reactivity order $\mathrm{R}_{\mathrm{N}}$ is $R_{3}>R_{2}>R_{1}>R_{0}$ (N infers the number of residues).

The comparison of the four reaction pathways, in Figure 3, further proves our conclusion. It shows that the reaction barriers of these four reactions have the order $\Delta E_{3}<\Delta E_{2}<\Delta E_{1}<\Delta E_{0}$, corresponding to the reactivity order $R_{3}>R_{2}>R_{1}>R_{0}$. Figure $3 \mathrm{~A}$ shows that the potential energy barriers with three, two, one and zero residues are $13.4,15.4,18.1$, and $22.2 \mathrm{kcal} / \mathrm{mol}$, respectively. In order to compare our reaction barriers with the experimental and theoretical values in terms of free energy, we calculated the free energies of these stationary points with Gaussian 16 package [37], as shown in Figure 3B. The reaction free energy barrier without any residues is the largest at $24.3 \mathrm{kcal} / \mathrm{mol}$, agreeing very well with a previous study of a MP2/6-31 + G* result at $23.2 \mathrm{kcal} / \mathrm{mol}$ [27], and the free energy barriers with one, two and three residues are 19.3, 17.1 and $15.4 \mathrm{kcal} / \mathrm{mol}$, respectively. The free energy barrier with three residues of $15.4 \mathrm{kcal} / \mathrm{mol}$ also agrees very well with experiment result at $15.3 \mathrm{kcal} / \mathrm{mol}$ [23]. This comparison proves that the presence of the residues enhances the reactivity, i.e., catalyzes the $S_{N} 2$ reaction, compared to the case with zero residues.

We plot the relationship between the distance difference descriptor $D_{c a t}$ and the free energy barrier in Figure 4A. The linear relationship between these two properties describes the catalytic power and catalytic performance- - that it is the surrounding residues around DCE that catalyze the $\mathrm{S}_{\mathrm{N}} 2$ reactivities. Additionally, the more residues that encompass the substrate, the bigger reactivity (catalytic power) the reaction has, with the three-residue case having the smallest activation barrier and largest reactivity. In other words, the presence of the enzyme speeds up the bond breaking and formation process in this $\mathrm{S}_{\mathrm{N}} 2$ step. 
A

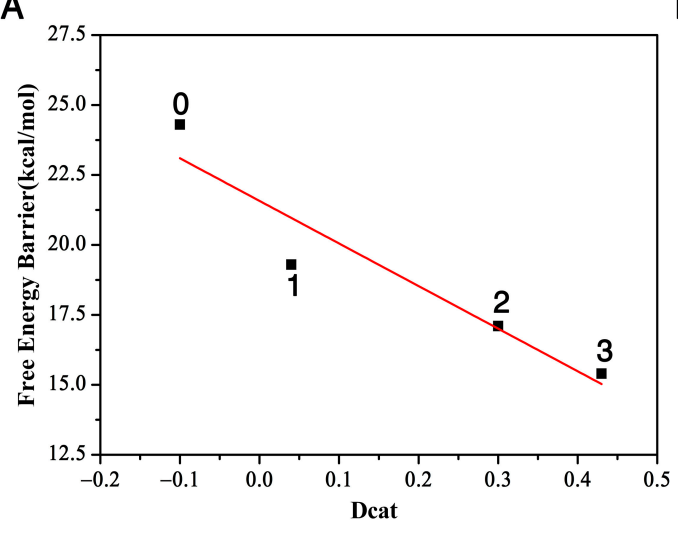

B

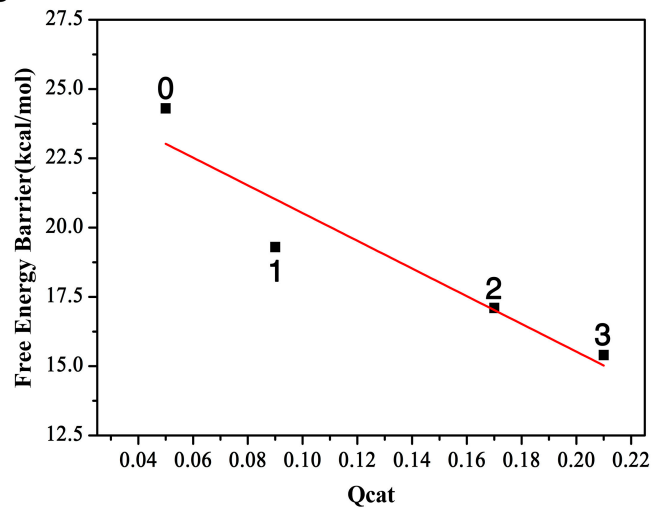

Figure 4. The relationship between the free energy barriers and the two descriptors, $\mathrm{D}_{\text {cat }}(\mathbf{A})$ and $\mathrm{Q}_{\text {cat }}(\mathbf{B})$, with three, two, one, and zero residues, respectively.

\subsection{The Charge Transfer Descriptor}

In this $\mathrm{S}_{\mathrm{N}} 2$ reaction process, the negative charge of nucleophile $\left(\mathrm{CH}_{3} \mathrm{CO}_{2}^{-}\right)$at the asymptote will gradually transfer to the leaving group $\mathrm{Cl}$ from the reactant complex to the transition state and then to the product complex. Let us define the charge transfer descriptor as $Q_{c a t}=q_{t s}-q_{r c}$. Here, $q_{t s}$ and $q_{r c}$ are calculated as the sum of the signed atomic charge values of the nucleophile, representing the charge of the nucleophile at the transition state and reactant complex, respectively. The bigger the $Q_{c a t}$ value is, the faster the charge transferred from the nucleophile to the leaving group, and the bigger the reactivity. From Table 1, we can see that this number is 0.09 with one residue Trp125, 0.17 with two residues Trp125 + Trp175 and 0.21 with three residues Trp125 + Phe172 + Trp175, and only 0.05 without any residues. The order of the charger transfer descriptor is $Q_{\text {cat }}(3)>Q_{\text {cat }}(2)>Q_{\text {cat }}(1)>Q_{\text {cat }}(0)$. This further demonstrates that the presence of the enzyme catalyzes the $\mathrm{AcO}^{-}+D C E$ reaction. The relationship between the charge-transfer descriptor $Q_{c a t}$ and the free energy barrier $\Delta \mathrm{E}$ is plotted in Figure $4 \mathrm{~B}$. It also shows a linear relationship, namely that, as the number of residues increases from zero to three, the activation barrier decreases. Compared to the reaction without residues, the presence of the enzyme speeds up the charge transfer rate of the $S_{N} 2$ process, catalyzing the $S_{N} 2$ process.

Table 1. The charge distributions of the key atoms or groups of the reactant complexes (RC), transition states (TS) for the $\mathrm{AcO}^{-}+\mathrm{DCE}$ reaction in the presence of three, two, one and zero residues, as well as the reaction in water solution. (The detailed charge distributions of the RC, TS and product complexes are listed in Table S1 of the Supplementary Materials.)

\begin{tabular}{ccccccccccc}
\hline & \multicolumn{3}{c}{$\mathbf{3}$} & \multicolumn{2}{c}{$\mathbf{2}$} & & $\mathbf{1}$ & & $\mathbf{0}$ & \multicolumn{2}{c}{ Water } \\
\hline & $\mathbf{R C}_{\mathbf{3}}$ & $\mathbf{T S}_{\mathbf{3}}$ & $\mathbf{R C}_{\mathbf{2}}$ & $\mathbf{T S}_{\mathbf{2}}$ & $\mathbf{R C}_{\mathbf{1}}$ & $\mathbf{T S}_{\mathbf{1}}$ & $\mathbf{R C}_{\mathbf{0}}$ & $\mathbf{T S}_{\mathbf{0}}$ & $\mathbf{R C}_{\text {sol }}$ & $\mathbf{T S}_{\text {sol }}$ \\
\hline $\mathrm{O} 1$ & -0.88 & -0.80 & -0.87 & -0.81 & -0.87 & -0.86 & -0.86 & -0.85 & -0.80 & -0.55 \\
$\mathrm{C}_{2} \mathrm{H}_{4} \mathrm{Cl}$ & 0.33 & 0.53 & 0.34 & 0.52 & 0.33 & 0.52 & 0.31 & 0.47 & 0.27 & 0.42 \\
$\mathrm{Cl} 1$ & -0.34 & -0.70 & -0.36 & -0.68 & -0.35 & -0.63 & -0.37 & -0.58 & -0.28 & -0.46 \\
$\mathrm{H} 1$ & 0.26 & 0.27 & 0.28 & 0.29 & 0.27 & 0.32 & & & \\
$\mathrm{H} 2$ & 0.30 & 0.31 & 0.29 & 0.31 & & & & & \\
$\mathrm{H} 3$ & 0.11 & 0.09 & & & & & & -0.89 & -0.66 & -0.62 \\
$\mathrm{CH}_{3} \mathrm{CO}_{2}$ & -0.94 & -0.73 & -0.94 & -0.77 & -0.94 & -0.85 & -0.94 & -0.89 & \\
\hline
\end{tabular}

So why does the presence of this enzyme enhance bond breaking and formation, as well as the charger transfer mechanism? As the $S_{N} 2$ dynamics evolves, the negative charge is gradually transferred from the nucleophile to the leaving group. As the leaving group Cl1 becomes more negative, it creates an electric field that interacts with the active-sites of the residues, giving rise to an induction energy which acts as a strong long-range attractive potential in addition to the van der Waals potential. This long-range attractive potential can significantly reduce the barrier to chemical rearrangement [38]. Additionally, this has been 
demonstrated in the activation barrier heights, in Figure 3A, in the presence of aromatic rings. Compared to the zero-residue case without induction energy, with the presence of the attractive induction potential energy, the barrier height with one residue Trp125 is reduced by $4.1 \mathrm{kcal} / \mathrm{mol}$. With the two-residue case, the barrier is further lowered by another $2.7 \mathrm{kcal} / \mathrm{mol}$ since the negative $\mathrm{Cl}$ charge now polarizes the two residues and produces two parts of attractive induction energy. With three residues, $\operatorname{Tr} 125+\operatorname{Tr} p 175$ + Phe172, the barrier height is reduced further by another $2.0 \mathrm{kcal} / \mathrm{mol}$ to the smallest at $13.4 \mathrm{kcal} / \mathrm{mol}$.

From the structural point of view in Figure 2, the three aromatic rings are all in the front side of the leaving group, i.e., the bond-breaking direction. Thus, the induction attractive potentials between the leaving group and the residues exert a pulling force from the residues to the leaving group, speeding up the bond breaking of the leaving group from the substrate, as well as the negative-charge transfer process.

\subsection{Prediction of the Reactivity in Water}

We have already obtained two descriptors of the catalytic effects in previous sections: the first descriptor is $D_{c a t}$, and the second is $Q_{c a t}$, both scaling linearly with the free energy barrier. Therefore, using the QM/MM approach, we can first obtain the $D_{c a t}$ and $Q_{c a t}$ values in water; then, according to the two descriptors, we can predict the barrier height in water to see if the water environment catalyzes or hinders the reactivity. Furthermore, the predicted barrier height can be compared with our calculated one in water using the $\mathrm{QM} / \mathrm{MM}$ method to confirm the prediction values.

The structures of the three stationary points (reactant complex, transition state and product complex) in the $\mathrm{AcO}^{-}$attacking DCE in water are inserted in Figure 5. The comparison of the $D_{\text {cat }}$ and $Q_{\text {cat }}$ values of this reaction with three residues (the far left column in Figure 2) and the ones in water tells us two different stories. At transition states, this Cl1-C1 bond length becomes $2.47 \AA$ with three residues, while it is shorter, only $2.14 \AA$, in water. In the meantime, the formation bond O1-C1 is $2.04 \AA$ with three residues, which is much longer, $2.24 \AA$, in water. The shorter length of the breaking bond and the longer length of the formation bond in water indicate that the water environment hinders the reactivity. Indeed, the $D_{\text {cat }}$ value is 0.43 for the reaction with three residues and is only -0.10 in water. According to the relationship between $D_{c a t}$ and the free energy barrier in Figure $4 \mathrm{~A}$, we can predict that the reaction barrier in the water environment is about $23.1 \mathrm{kcal} / \mathrm{mol}$, about $7.7 \mathrm{kcal} / \mathrm{mol}$ larger than with three residues at $15.4 \mathrm{kcal} / \mathrm{mol}$. Furthermore, Table 1 tells us the $Q_{\text {cat }}$ value in water is 0.04 , which is much smaller than with three residues, 0.21 , in water; thus, according to the relationship between $Q_{c a t}$ and the free energy barrier in Figure $4 \mathrm{~B}$, we can predict that the energy barrier in the water environment is about $24.2 \mathrm{kcal} / \mathrm{mol}$, which is $8.8 \mathrm{kcal} / \mathrm{mol}$ larger than the one with three residues. Therefore, the enzyme environment enhances the reaction reactivity, while the water environment actually hinders the reactivity.

Figure 5 shows the NEB reaction pathway in water calculated with the QM/MM approach. The calculated free energy barrier height of the transition state is $25.2 \mathrm{kcal} / \mathrm{mol}$, which agrees very well with the one predicted with the $D_{\text {cat }}$ descriptor at about $23.1 \mathrm{kcal} / \mathrm{mol}$, while also in agreement with the $\mathrm{Q}_{\text {cat }}$ predicted one at about $24.2 \mathrm{kcal} / \mathrm{mol}$. Therefore, in contrast to the barrier height with three residues at $15.4 \mathrm{kcal} / \mathrm{mol}$, it tells us the water solvent impedes the reactivity. Note both predicted barrier heights of $23.1 \mathrm{kcal} / \mathrm{mol}$ and $24.2 \mathrm{kcal} / \mathrm{mol}$ agree well with the calculated free energy barrier height of $25.2 \mathrm{kcal} / \mathrm{mol}$ in water, and also agree well with the experimental value at $26.0 \mathrm{kcal} / \mathrm{mol}$ [26]. 


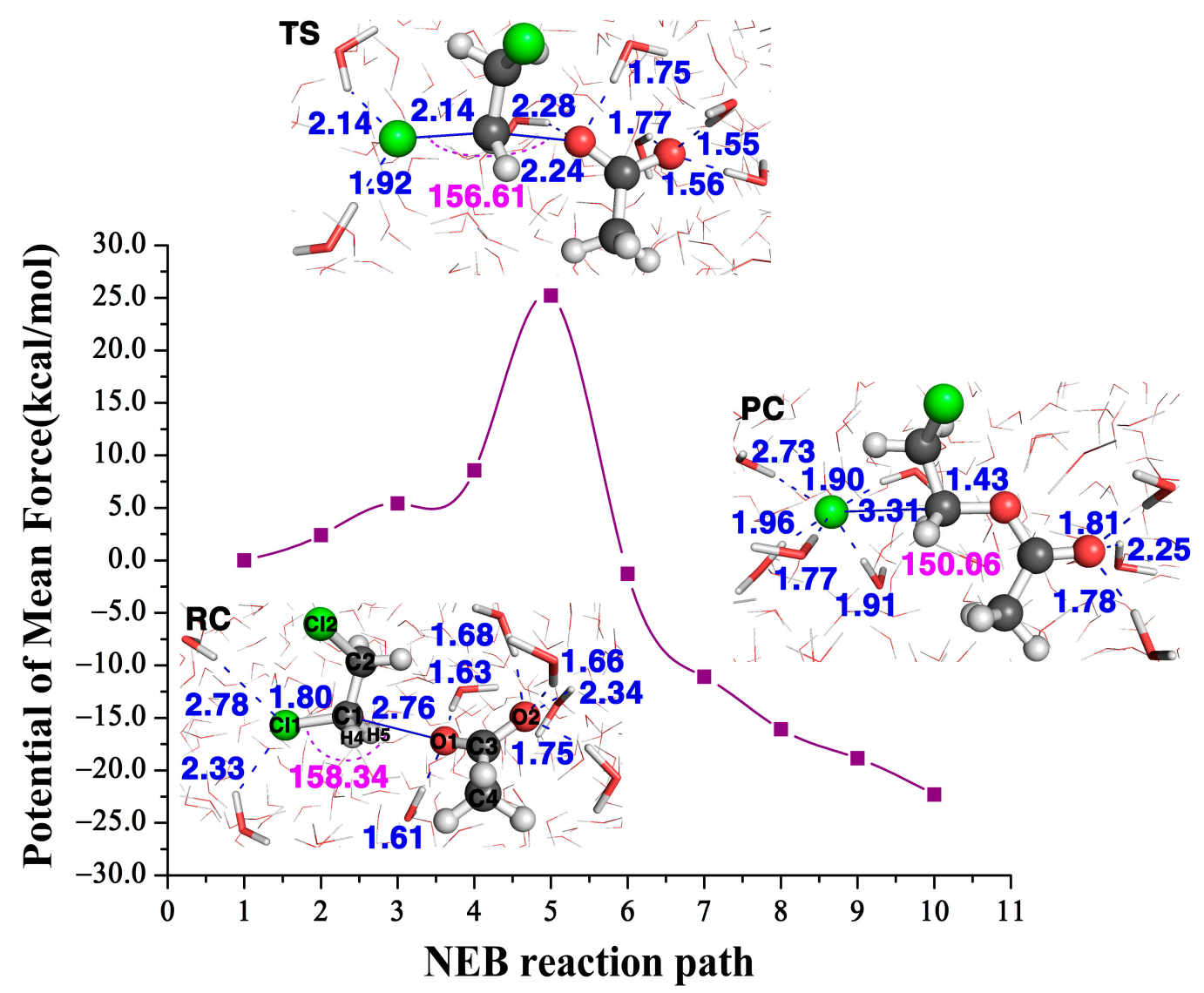

Figure 5. The NEB reaction path of the $\mathrm{ACO}^{-}+\mathrm{DCE}$ reaction and the structures of its reactant complex (RS), transition state (TS) and product complex (PC) in water.

As this reaction takes place in water, on one hand, as the negative charge gradually transfers from the nucleophile $\mathrm{AcO}^{-}$to the leaving group $\mathrm{Cl1}$, it should also induce the attractive long-range potential between the leaving group $\mathrm{Cl} 1$ and its surrounding water molecules. However, the water molecules surrounding the leaving group are not only in its frontside, bond-breaking direction, but also in the backside direction. Namely, the water molecules are not orderly distributed around the leaving group. As a result, the polarized water molecules do not exert a uniform, forward pulling force to the leaving group. Of course, to explicitly investigate the role of the water molecules surrounding the leaving group and the nucleophile $\mathrm{AcO}^{-}$in the QM/MM calculation, it would be better to include at least the water molecules in the first-solvation shell in the QM region. Nonetheless, the water molecules usually undergo of the order of $10^{13}$ collisions per second with the solute molecule [38], which hinders the separation between the leaving group and the substrate in the $\mathrm{S}_{\mathrm{N}} 2$ step. Furthermore, previous calculations using the current $\mathrm{QM} / \mathrm{MM}$ method with an explicit SPC/E water model on the $\mathrm{S}_{\mathrm{N}} 2$ reactions of $\mathrm{OH}^{-}+\mathrm{CH}_{3} \mathrm{Br}$ [39] and $\mathrm{CN}^{-}+$ $\mathrm{CH}_{3} \mathrm{Cl}$ [40], without the water molecules in the QM region, give accurate activation barriers compared to the experimental ones.

On the other hand, at the transition state structure, $\mathrm{O} 1$ in the nucleophile forms two hydrogen bonds with surrounding water molecules, which reduces its negativity, thus reducing its interaction with the $\mathrm{Cl} 1$ center. In addition, $\mathrm{O} 2$ has three hydrogen bond interactions with the water molecules at its backside, pulling it back from the attacking direction. Therefore, we can conclude, in a water environment, the interactions with the surrounding water molecules, especially the hydrogen bond interactions surrounding the nucleophile, hinder its reactivity. Therefore, in a water environment, the reactivity is impeded. 


\section{Methodologies}

3.1. Quantum Mechanics Calculation for the $\mathrm{AcO}^{-}+D C E$ with Three, Two, One, and Zero Residues

The reaction pathway of $\mathrm{AcO}^{-}+D C E$ was computed using Density Function Theory (DFT) quantum level of theory with 6-31 $+\mathrm{G}^{* *}$ basis set [41]. The M08-HX exchange correlation functional was used for the DFT calculation due to its accuracy in predicting the bond lengths of aromatic rings, the non-covalent interactions of larger molecules and the reaction barrier heights [42]. First, the structure in Figure 1B was optimized as the reactant complex, and the product complex was searched from the reaction complex according to the $\mathrm{S}_{\mathrm{N}} 2$ mechanism. Second, the Nudged Elastic Band (NEB) method [43] was adopted to construct the reaction pathway using the reactant complex and product complex. Then, the top structure on the reaction pathway was confirmed as the transition state with one imaginary vibrational frequency. The displacements of the imaginary-vibrational-frequency mode of the transition state were used to locate the final reactant and product complexes. Finally, the final NEB reaction pathway was constructed based on the final reactant, transition state and product complexes. The evolutions of the structures, charges, and energies along the reaction pathway of the whole reaction system were then determined.

In this theoretical study, the Trp125, Trp175, and Phe172 residues were removed one by one from the enzyme to see the partial and whole enzyme catalytic effects on the reaction pathways. The calculations of the reaction pathways of $\mathrm{AcO}^{-}+D C E$ with two aromatic rings (Trp125, Trp175), with one aromatic ring (Trp 125) and without aromatic rings were carried out using the same method, respectively.

\subsection{Quantum Mechanics and Molecular Mechanics Calculation for $\mathrm{AcO}^{-}+D C E$ in Water}

For the $\mathrm{AcO}^{-}+D C E$ reaction in water, we employed a QM/MM approach $[32,33]$ to calculate its reaction path in water. We treated the whole reaction system as two parts: we used the quantum mechanical method to treat the solute region $\mathrm{AcO}^{-}+\mathrm{DCE}$ and molecular mechanics method for the water molecules. The QM solute was solvated into a $37.5 \AA$ cubic water box with 1762 water molecules described by an explicit SPC/E water model [44]. The potential energy of the whole system can be expressed as:

$$
V=V_{q m}(r, \varphi)+V_{q m / m m}(r, R, \rho)+V_{m m}(R)
$$

The first term $V_{q m}(r, \varphi)$ represents the QM energy of the solute subsystem in the gas phase. The $r$ and $\varphi$ in the expression represent the coordinates and ground-state electronic wave function of the QM region, respectively. The second term $V_{q m / m m}(r, R, \rho)$ describes the solute and solvent electrostatic interactions. The solute-solvent bond interactions, and van der Waals interactions, as well as the interactions of the solvent subsystem are included in the third term $V_{m m}(R)$, where R stands for the coordinate of the MM region. The electrostatic interaction contribution can be described approximately by effective electrostatic potential (ESP) for the solute-solvent interactions [45]. The ESP representation forms the base-level theory for the QM region. For the DFT level of theory calculation, the same DFT/M08-HX/6-31 + G** combination is used as described in Section 2.1.

The potential of mean force (PMF) along the reaction pathway in water solution was calculated as:

$$
W(r, \beta)=-\frac{1}{\beta} \ln \int e^{-\beta V(r, R ; \varphi)} d R \quad \beta=\frac{1}{k T}
$$

After the $\mathrm{AcO}^{-}+D C E$ reactant complex was solvated and optimized using a multiregion optimization in water, we searched the product complex according to the $S_{N} 2$ mechanism, and then constructed an initial NEB reaction pathway. In this initial NEB reaction pathway, we confirmed the top structure on the reaction pathway with one imaginary frequency. Based on this transition state, along the negative frequency vibrational mode, we searched and determined the new reactant and product complexes to construct the NEB pathway again. The dynamical equilibration of the solvent water molecules for $120 \mathrm{ps}$ and 
then the optimization of the entire reaction pathway were performed until the reaction pathway converged. The above reaction pathway calculations were performed using the NWChem package [46].

\section{Conclusions}

In this paper, we present a theoretical study of using reactive descriptors to explore the catalytic power in the $S_{N} 2$ reaction of the haloalkane dehalogenase enzyme with 1,2dichloroethane. We found two catalytic descriptors that have a linear relationship with the reaction barriers. One is the distance difference $D_{c a t}$ of the breaking bond and the forming bond, and the other is the charge difference $Q_{\text {cat }}$ of the nucleophile between the transition state and reactant complex. Both descriptors demonstrate that as the number of residues increases, the reaction barriers decrease, thus the catalytic power increases. The two descriptors indicate that the presence of the residues speeds up the $\mathrm{S}_{\mathrm{N}} 2$ bond breaking and formation process and also enhances the charge transfer process. Therefore, the presence of enzymes catalyzes the $\mathrm{S}_{\mathrm{N}} 2$ reaction.

The two catalytic descriptors were also used to predict the reaction barrier of this reaction in water. The activation barrier predicted with the $D_{\text {cat }}$ descriptor is about $23.1 \mathrm{kcal} / \mathrm{mol}$, and the one predicted with $Q_{\text {cat }}$ is about $24.2 \mathrm{kcal} / \mathrm{mol}$. Both agree well with the experimental result at $26.0 \mathrm{kcal} / \mathrm{mol}$. These results mean that the water environment hinders this $S_{N} 2$ reaction. The two descriptors we found in this theoretical study show that reactive descriptors can also be developed in enzyme catalysis to explain the catalytic power and to describe the performance of its reactivity. They might also be used to design effective enzyme catalytic reactions such as in environmental detoxification processes.

Supplementary Materials: The Supplementary Materials are available online at https:/ /www.mdpi. com/article/10.3390/ijms22115854/s1.

Author Contributions: Conceptualization, D.W. and X.X.; methodology, D.W.; validation, C.L. and D.G.; formal analysis, X.X. and D.W.; investigation, X.X.; original draft preparation, X.X.; writingreview and editing, D.W.; visualization, X.X.; supervision, D.W.; project administration, D.W.; funding acquisition, D.W. All authors have read and agreed to the published version of the manuscript.

Funding: This work was supported by the National Natural Science Foundation of China (Grant No. 11774206).

Institutional Review Board Statement: Not applicable.

Informed Consent Statement: Not applicable.

Data Availability Statement: The data presented in this study are available in this article and supplementary materials.

Acknowledgments: This work was supported by the National Natural Science Foundation of China (Grant No. 11774206). The computation was carried out at the Shenzhen Supercomputer Center in China.

Conflicts of Interest: The authors declare no conflict of interest.

\section{References}

1. Warshel, A. Computer Modeling of Chemical Reactions in Enzymes and Solutions; Wiley-Interscience: New York, NY, USA, 1991.

2. Fersht, A. Structure and Mechanism in Protein Science: A Guide to Enzyme Catalysis and Protein Folding; W.H. Freeman and Co.: New York, NY, USA, 1999.

3. Janssen, D.B.; Scheper, A.; Dijkhuizen, L.; Witholt, B. Degradation of halogenated aliphatic compounds by Xanthobacter autotrophicus GJ10. Appl. Environ. Microb. 1985, 49, 673-677. [CrossRef]

4. Warshel, A.; Sharma, P.K.; Kato, M.; Xiang, Y.; Liu, H.; Olsson, M.H.M. Electrostatic basis for enzyme catalysis. Chem. Rev. 2006, 106, 3210-3235. [CrossRef] [PubMed]

5. Kamerlin, S.C.L.; Warshel, A. At the dawn of the 21st century: Is dynamics the missing link for understanding enzyme catalysis? Proteins 2010, 78, 1339-1375. [CrossRef] [PubMed]

6. Warshel, A.; Bora, R.P. Perspective: Defining and quantifying the role of dynamics in enzyme catalysis. J. Chem. Phys. 2016, 144, 180901. [CrossRef] [PubMed] 
7. Warshel, A. Energetics of enzyme catalysis. Proc. Natl. Acad. Sci. USA 1978, 75, 5250-5254. [CrossRef]

8. Soriano, A.; Silla, E.; Tunon, I.; Marti, S.; Moliner, V.; Bertran, J. Electrostatic effects in enzyme catalysis: A quantum mechan$\mathrm{ics} /$ molecular mechanics study of the nucleophilic substitution reaction in haloalkane dehalogenase. Theor. Chem. Acc. 2004, 112, 327-334. [CrossRef]

9. Soriano, A.; Silla, E.; Tuñón, I.; Ruiz-López, M.F. Dynamic and electrostatic effects in enzymatic processes. An analysis of the nucleophilic substitution reaction in haloalkane dehalogenase. J. Am. Chem. Soc. 2005, 127, 1946-1957. [CrossRef]

10. Olsson, M.H.M.; Parson, W.W.; Warshel, A. Dynamical contributions to enzyme catalysis: Critical tests of a popular hypothesis. Chem. Rev. 2006, 106, 1737-1756. [CrossRef]

11. Careri, G.; Fasella, P.; Gratton, E. Enzyme dynamics: The statistical physics approach. Ann. Rev. Biophys. Bioeng. 1979, 8, 69-97. [CrossRef]

12. Neria, E.; Kuplus, M. Molecular dynamics of an enzyme reaction: Proton transfer in TIM. Chem. Phys. Lett. 1997, 267, 23-30. [CrossRef]

13. Nam, K.; Prat-Resina, X.; Garcia-Viloca, M.; Devi-Kesavan, L.S.; Gao, J. Dynamics of an enzymatic substitution reaction in haloalkane dehalogenase. J. Am. Chem. Soc. 2004, 126, 1369-1376. [CrossRef]

14. Henzler-Wildman, K.A.; Thai, V.; Lei, M.; Ott, M.; Wolf-Watz, M.; Fenn, T.; Pozharski, E.; Wilson, M.A.; Petsko, G.A.; Karplus, M.; et al. Intrinsic motions along an enzymatic reaction trajectory. Nature 2007, 450, 838-844. [CrossRef]

15. Bhabha, G.; Lee, J.; Ekiert, D.C.; Gam, J.; Wilson, L.A.; dyson, H.J.; Benkovic, S.J.; Wright, P.E. A dynamic knockout reveals that conformational fluctuations influence the chemical step of enzyme catalysis. Science 2011, 332, 234-238. [CrossRef] [PubMed]

16. García-Meseguer, R.; Martí, S.; Ruiz-Pernía, J.J.; Moliner, V.; Tuñón, I. Studying the role of protein dynamics in an SN2 enzyme reaction using free-energy surfaces and solvent coordinates. Nat. Chem. 2013, 5, 566-571. [CrossRef]

17. Singh, P.; Francis, K.; Kohen, A. Network of remote and local protein dynamics in dihydrofolate reductase catalysis. ACS Catal. 2015, 5, 3067-3073. [CrossRef] [PubMed]

18. Keuning, S.; Janssen, D.B.; Witholt, B. Purification and characterization of hydrolytic haloalkane dehalogenase from Xanthobacter autotrophicus GJ10. J. Bacteriol. 1985, 163, 635-639. [CrossRef]

19. Janssen, D.B.; Pries, F.; Van der Ploeg, J.; Kazemier, B.; Terpstra, P.; Witholt, B. Cloning of 1,2-dichloroethane degradation genes of Xanthobacter autotrophicus GJ10 and expression and sequencing of the dhlA gene. J. Bacteriol. 1989, 17, 6791-6799. [CrossRef] [PubMed]

20. Tardif, G.; Greer, C.W.; Labbe, D.; Lau, P.C. Involvement of a large plasmid in the degradation of 1,2-dichloroethane by Xanthobacter autotrophicus. Appl. Environ. Microb. 1991, 57, 1853-1857. [CrossRef]

21. Franken, S.M.; Rozeboom, H.J.; Kalk, K.H.; Dijkstra, B.W. Crystal structure of haloalkane dehalogenase: An enzyme to detoxify halogenated alkanes. EMBO J. 1991, 10, 1297-1302. [CrossRef]

22. Verschueren, K.H.G.; Franken, S.M.; Rozeboom, H.J.; Kalk, K.H.; Dijkstra, B.W. Refined X-ray Structures of Haloalkane Dehalogenase at pH6.2 and pH8.2 and Implications for the Reaction Mechanism. J. Mol. Biol. 1993, 232, 856-872. [CrossRef]

23. Schanstra, J.P.; Ridder, I.S.; Heimeriks, G.J.; Rink, R.; Poelarends, G.J.; Kalk, K.H.; Dijkstra, B.W.; Janssen, D.B. Kinetic characterization and $X$-ray structure of a mutant of haloalkane dehalogenase with higher catalytic activity and modified substrate range. Biochemistry 1996, 35, 13186-13195. [CrossRef]

24. Damborský, J.; Kutý, M.; Němec, M.; Koca, J. A molecular modeling study of the catalytic mechanism of haloalkane dehalogenase: 1. quantum chemical study of the first reaction step. J. Chem. Inf. Comput. Sci. 1997, 37, 562-568. [CrossRef]

25. Kutý, M.; Damborský, J.; Prokop, M.; Koca, J. A molecular modeling study of the catalytic mechanism of haloalkane dehalogenase. 2. quantum chemical study of complete reaction mechanism. J. Chem. Inf. Comput. Sci. 1998, 38, 736-741. [CrossRef]

26. Shurki, A.; Strajbl, M.; Villa, J.; Warshel, A. How much do enzymes really gain by restraining their reacting fragments? J. Am. Chem. Soc. 2002, 124, 4097-4107. [CrossRef] [PubMed]

27. Devi-Kesavan, L.S.; Gao, J. Combined QM/MM study of the mechanism and kinetic isotope effect of the nucleophilic substitution reaction in haloalkane dehalogenase. J. Am. Chem. Soc. 2003, 125, 1532-1540. [CrossRef] [PubMed]

28. Hur, S.; Kahn, K.; Bruice, T.C. Comparison of formation of reactive conformers for the SN2 displacements by $\mathrm{CH}_{3} \mathrm{CO}_{2}^{-}$in water and by Asp $-\mathrm{CO}_{2}^{-}$in a haloalkane dehalogenase. Proc. Natl. Acad. Sci. USA 2003, 100, 2215-2219. [CrossRef] [PubMed]

29. Verschueren, K.H.G.; Seljée, F.; Rozeboom, H.J.; Kalk, K.H.; Dijkstra, B.W. Crystallographic analysis of the catalytic mechanism of haloalkane dehalogenase. Nature 1993, 363, 693-698. [CrossRef] [PubMed]

30. Rosta, E.; Klähn, M.; Warshel, A. Towards accurate ab initio QM/MM calculations of free-energy profiles of enzymatic reactions J. Phys. Chem. B 2006, 110, 2934-2941. [CrossRef]

31. Lau, E.Y.; Kahn, K.; Bash, P.A.; Bruice, T.C. The importance of reactant positioning in enzyme catalysis: A hybrid quantum mechanics/molecular mechanics study of a haloalkane dehalogenase. Proc. Natl. Acad. Sci. USA 2000, 97, 9937-9942. [CrossRef]

32. Liu, P.; Wang, D.; Xu, Y. A new, double-inversion mechanism of the $F^{-}+\mathrm{CH}_{3} \mathrm{Cl} \mathrm{SN2}$ reaction in aqueous solution. Phys. Chem. Chem. Phys. 2016, 18, 31895-31903. [CrossRef]

33. Wang, T.; Yin, T.; Wang, T.; Valiev, M. Hybrid Quantum Mechanical and Molecular Mechanics Study of the SN2 Reaction of $C C l_{4}$ $+\mathrm{OH}^{-}$in Aqueous Solution: The Potential of Mean Force, Reaction Energetics, and Rate Constants. J. Phys. Chem. A 2012, 116, 2371-2376. [CrossRef]

34. Zhao, Z.J.; Liu, S.; Zha, S.; Cheng, D.; Studt, F.; Henkelman, G.; Gong, J. Theory-guided design of catalytic materials using scaling relationships and reactivity descriptors. Nat. Rev. Mater. 2019, 4, 792-804. [CrossRef] 
35. Zhang, L.; Lin, C.Y.; Zhang, D.; Gong, L.; Zhu, Y.; Zhao, Z.; Xu, Q.; Li, H.; Xia, Z. Guiding Principles for Designing Highly Efficient Metal-Free Carbon Catalysts. Adv. Mater. 2019, 31, 1805252. [CrossRef]

36. Eyring, H. The activated complex in chemical reactions. J. Chem. Phys. 1935, 3, 107. [CrossRef]

37. Frisch, M.J.; Trucks, G.W.; Schlegel, H.B.; Scuseria, G.E.; Robb, M.A.; Cheeseman, J.R.; Scalmani, G.; Barone, V.; Petersson, G.A.; Nakatsuji, H.; et al. GAUSSIAN 16, Revision A. 03; Gaussian, Inc.: Wallingford, CT, USA, 2016.

38. Levine, R.D. Molecular Reaction Dynamics; Cambridge University Press: New York, NY, USA, 2005; p. 427.

39. $\mathrm{Xu}, \mathrm{Y}$;; Wang, T.; Wang, D. A multilayered-representation quantum mechanical/molecular mechanics study of the $\mathrm{S}_{\mathrm{N}} 2$ reaction of $\mathrm{CH}_{3} \mathrm{Br}+\mathrm{OH}^{-}$in aqueous solution. J. Chem. Phys. 2012, 137, 184501. [CrossRef] [PubMed]

40. Xu, Y.; Zhang, J.; Wang, D. Investigation of the $\mathrm{CH}_{3} \mathrm{Cl}+\mathrm{CN}^{-}$reaction in water: Multilevel quantum mechanics/molecular mechanics study. J. Chem. Phys. 2015, 142, 244505. [CrossRef]

41. Petersson, G.A.; Al-Laham, M.A. A complete basis set model chemistry. II. Open-shell systems and the total energies of the first-row atoms. J. Chem. Phys. 1991, 94, 6081-6090. [CrossRef]

42. Zhao, Y.; Truhlar, D.G. Exploring the limit of accuracy of the global hybrid meta density functional for main-group thermochemistry, kinetics, and noncovalent interactions. J. Chem. Theory Comput. 2008, 4, 1849-1868. [CrossRef]

43. Henkelman, G.; Uberuaga, B.P.; Jónsson, H. A climbing image nudged elastic band method for finding saddle points and minimum energy paths. J. Chem. Phys. 2000, 113, 9901-9904. [CrossRef]

44. Berendsen, H.J.C.; Grigera, J.R.; Straatsma, J.R. The missing term in effective pair potentials. J. Phys. Chem. 1987, 91, 6269-6271. [CrossRef]

45. Zhang, Y.; Liu, H.; Yang, W. Free energy calculation on enzyme reactions with an efficient iterative procedure to determine minimum energy paths on a combined ab initio QM/MM potential energy surface. J. Chem. Phys. 2000, 112, 3483-3492. [CrossRef]

46. Valiev, M.; Bylaska, E.J.; Govind, N.; Kowalski, K.; Straatsma, T.P.; Van Dam, H.J.J.; Wang, D.; Nieplocha, J.; Aprab, E.; Windus, T.L.; et al. NWChem: A comprehensive and scalable open-source solution for large scale molecular simulations. Comput. Phys. Commun. 2010, 181, 1477-1489. [CrossRef] 